\title{
A língua/linguagem e o jogo de xadrez: perspectivas teóricas em Saussure e Wittgenstein
}

\section{Language and the game of chess: theorectical perspectives in Saussure and Wittgenstein}

Camila Pilotto Figueiredo*

RESUMO: O presente artigo possui como objetivo abordar a noção de língua/linguagem em Saussure e em Wittgenstein através de suas analogias com o jogo de xadrez. Iniciaremos apresentando a metáfora do jogo de xadrez em cada um dos pensadores, evidenciando como as analogias por eles realizadas se inserem em suas teorias e, em consequência, elucidam seus pontos de vista acerca da noção de língua/linguagem; por fim, faremos uma análise comparativa das analogias de ambos os pensadores, avaliando em que medida elas se aproximam e se distanciam umas das outras, além de observarmos os limites de aproximação entre língua e jogo de xadrez em cada analogia.

PALAVRAS-CHAVE: língua/linguagem; jogo de xadrez; Saussure; Wittgenstein.

ABSTRACT: This article aims to address the notion of language in Saussure and Wittgenstein through their analogies with the game of chess. We will start by presenting the metaphor of the chess game in each of the thinkers, showing how the analogies they make are inserted in their theories and elucidate their language perspectives; finally, we will make a comparative analysis of the analogies of both thinkers, evaluating the extent to which they approach and distance themselves from each other, in addition to observing the limits of approximation between language and chess game in each analogy.

KEYWORDS: language; chess game; Saussure; Wittgenstein.

\footnotetext{
* Mestra em Filosofia pela Universidade Federal de Pelotas. Graduanda no curso de Letras Português e Francês pela mesma instiuição. E-mail: figueiredo.camilapilotto@gmail.com.
} 


\section{Introdução}

Ao longo do percurso dos estudos em linguagem, diversos pensadores se utilizaram de analogias e metáforas ${ }^{41}$ com o objetivo de esclarecer algum ponto acerca da língua/linguagem ${ }^{42}$. Curiosamente, uma metáfora que se mostrou bastante corrente nesses estudos foi a da língua/linguagem como jogo de xadrez. Leibniz, Saussure, Hjelmslev, Frege, Wittgenstein e Greimas são alguns dos nomes de autores que relacionaram tais elementos (DUCARD, 2017; GUSTAFSSON, 2017). Dentre essa gama de estudiosos a realizarem tais aproximações, dois deles se destacaram em suas analogias: Ferdinand de Saussure (2006), que tem, entre suas preocupações, o estabelecimento do objeto da linguística e a compreensão de sua natureza; e o filósofo Ludwig Wittgenstein (1999), que, nas Investigações Filosóficas (IF), funda uma teoria pragmática do significado.

É de fácil compreensão a decisão de tais autores em utilizarem-se de metáforas e analogias por sabermos que, quando bem empregadas, ambas são instrumentos de ensino valiosos 43 . Entretanto, a utilização de analogias,

\footnotetext{
${ }^{41}$ De acordo com Reinders Duit (1991), uma analogia requer que duas estruturas distintas sob algum aspecto sejam explicitamente comparadas, mas tal comparação não deve ser feita de qualquer modo: deve haver identidade entre partes das estruturas que se busca comparar. Ainda, uma analogia requer sempre um elemento mais conhecido (analog) que se compara ao menos conhecido (target) a fim de elucidá-lo. Diferentemente das analogias, metáforas são descritas por Duit (1991) como comparações não tão explícitas entre elementos, de modo que a essência da metáfora seria esse ocultamento inicial dos aspectos de comparação. Nesse sentido, metáforas não podem ser compreendidas de modo literal e sempre possuem um aspecto de surpresa. Dizemos, pois, que a relação entre ambas fica evidente quando buscamos compreender o significado de uma metáfora, pois tanto o ouvinte como o enunciador desta apelarão a analogias para torná-la compreensível. Se resumirmos, então, parte do pensamento de Saussure (2006) e Wittgenstein (1999), afirmando que, para eles, a linguagem é (como) um jogo de xadrez, estaremos aqui enunciando uma metáfora que necessitará, para se sustentar, de analogias que mostrem como tais elementos se identificam. Considerando o que foi dito, utilizaremos, em nosso escrito, analogias como elementos necessários para justificar a metáfora da linguagem como jogo de xadrez.

${ }^{42}$ Ao longo do artigo o leitor encontrará frequentemente os termos língua/linguagem lado a lado. Tal ocorrência é devida ao fato de que Saussure (2002; 2006) abordará a metáfora do jogo de xadrez para esclarecer a noção de língua, enquanto Wittgenstein (1999) utilizará a metáfora para pensar sobre a linguagem.

${ }^{43}$ Segundo Duit (1991), sempre aprendemos algo novo a partir da reconstrução de similaridades entre o novo e o já conhecido. As analogias se prestam exatamente para que possamos conseguir aprender algo novo com maior facilidade. Assim, podemos elencar várias vantagens para o uso de
} 
especificamente entre jogo de xadrez e língua/linguagem é bastante curiosa, pois a relação entre ambos elementos não é imediatamente compreensível. Legítimo se faz questionar, então: em que medida é possível relacionar a dinâmica do jogo de xadrez à dinâmica da língua/linguagem?

O presente artigo possui como objetivo abordar a metáfora da língua/linguagem como jogo de xadrez em Saussure (2002; 2006) e Wittgenstein (1999) 44, evidenciando como ela auxilia na construção da visão de língua/linguagem de cada um deles e analisando em que medida as analogias de ambos os autores se relacionam. Para alcançarmos nosso objetivo, trataremos, num primeiro momento, do pensamento de cada autor individualmente para, em seguida, realizarmos nossa análise dos principais pontos de aproximação e distanciamento entre as analogias.

\section{Saussure e o jogo de xadrez}

Saussure (2006), no Curso de Linguística Geral (CLG), observa que, ao longo da história, deram-se saltos importantes nos estudos da língua; entretanto, questões fundamentais ainda estariam por ser respondidas. $\mathrm{O}$ autor coloca, então, como uma das tarefas da linguística "delimitar-se e definir a si própria" (SAUSSURE, 2006, p. 13). Tal tarefa seria essencial para o linguista, na medida em que ele poderia delimitar sua própria atividade e, assim, dissipar os erros provenientes do fato de haver tantas outras ciências que abordavam a língua sobre algum ponto de vista. Mais do que isso, definir o objeto da linguística permitiria elevá-la ao patamar de ciência.

analogias, entre elas, facilitar a compreensão de conceitos abstratos, permitir a visualização resumida de algum aspecto abordado, abrir novas perspecivas para a aprendizagem de conceitos etc.

44 Não temos a pretensão de realizar uma apresentação exaustiva das passagens em que ambos fazem uma analogia entre jogo de xadrez e a língua/linguagem, mas buscaremos apresentar as analogias mais relevantes presentes no Curso de Linguística Geral (2006) e nos Escritos de Linguística Geral (2002), de Saussure, bem como nas Investigações Filosóficas (1999), de Wittgenstein. 
Saussure (2006) explica que a linguística é uma ciência que lida com valores, e que todas as ciências assim caracterizadas possuem dois eixos: o eixo das simultaneidades - que diz respeito à relação entre elementos coexistentes e o eixo das sucessões - que tange a elementos que só podem ser considerados um por vez. O linguista afirma que, quanto mais organizadas e complexas forem tais ciências, mais será necessário estudá-las a partir desses dois eixos; desse modo, afirma podermos pensar a linguística através de seu desmembramento em duas outras áreas: linguística sincrônica e linguística diacrônica. Enquanto a linguística diacrônica opera no eixo das sucessões, abordando as relações entre termos sucessivos que se substituem uns aos outros, a linguística sincrônica tange ao eixo das simultaneidades, abordando as relações lógicas e psicológicas que unem termos coexistentes e que formam sistemas.

Embora as duas linguísticas sejam seu objeto de estudo, Saussure está interessado, primeiramente, em compreender a natureza da língua, voltando-se ao estudo sincrônico, já que é lá que a língua opera como sistema. Para mostrar como um sistema opera, Saussure (2006) afirma que um estado de jogo no xadrez equivale a um estado de língua, no sentido de que, assim como a cada estado de jogo, o valor das peças depende das suas relações com as demais. Na língua, o valor dos signos será determinado por suas relações de oposição aos demais termos do sistema. Isso significa que, isolados, os signos não existem enquanto tais. Observemos, pois, a seguinte passagem dos Escritos de Linguística Geral:

\footnotetext{
Assim como, no jogo de xadrez, seria absurdo perguntar o que seria uma dama, um bispo ou um cavalo, considerados fora do jogo de xadrez, assim também não tem sentido, quando se considera verdadeiramente a língua, buscar o que é cada elemento por si mesmo. Ele nada é além de uma peça que vale por oposição às outras, segundo certas convenções. (SAUSSURE, 2002, p. 63)
}

Dizer que um signo só possui valor a partir de suas relações de oposição aos demais termos da língua significa dizer que os signos não possuem valor por si mesmos, que o sistema não é o resultado de uma soma de signos e que o valor de cada termo resulta justamente da oposição. Logo, se um signo é retirado do sistema, não há mais oposição a ser feita a ele, o que significa que "fora das 
relações que o constituem como elemento de uma língua, perde sua realidade de signo, ou seja, não significa mais nada” (NORMAND, 2009, p. 159).

Mesmo tendo entendido que a língua é um sistema de signos e que os valores desses signos existem por oposição aos demais, podemos ainda indagar o que acontece quando um novo signo passa a ou deixa de existir nesse sistema. Quanto a esse questionamento, Saussure (2006) realiza três afirmações, no capítulo A Linguística Estática e a Linguística Evolutiva, que podem ser bem compreendidas se pensadas em suas relações.

Consideremos, primeiramente, as afirmações de que “cada lance do jogo movimenta apenas uma peça" e que "tal mudança repercute sobre todo o sistema" (SAUSSURE, 2006, p. 104). Quanto à dinâmica do jogo de xadrez, sabemos que cada lance realizado permite movimentar apenas uma peça. Entretanto, percebemos que tal movimentação modifica toda a configuração do jogo, de modo que as peças passam a se relacionar com as demais de modo diferente e têm seus valores transformados. Assim, uma peça que, num primeiro momento, não possui grande vantagem de movimentação devido à sua relação com as demais; em outra situação, pode muito bem ser útil movimentá-la para eliminar uma peça adversária. Dizemos, ainda, que cada movimentação ou pode gerar grandes reviravoltas no jogo, tendo consequências mesmo para as peças que não estavam envolvidas na jogada, ou pode ainda ter média ou ínfima importância para o novo estado de jogo que se sucederá ao lance realizado. Mas, de qualquer modo, cada jogada traz à tona um novo sistema, visto que a relação entre as peças se modifica.

De modo similar ao que ocorre no xadrez, as mudanças na língua se aplicam a elementos isolados; contudo, acabam por afetar todo o sistema, sendo impossível prever se a modificação de valor das peças será de grave, média ou pouca importância. Não importa, pois, se tais alterações são radicais ou sutis: na língua, cada mudança isolada de um termo gera a passagem de uma sincronia a outra, de um estado de língua a outro. Logo, se partirmos do que foi explicado e da compreensão de que a mutabilidade do valor dos signos é característica da língua, a afirmação de Saussure (2006, p. 104) de que "o sistema nunca é mais 
que momentâneo; varia de uma posição a outra”, decorre naturalmente das demais sentenças.

Apesar da movimentação característica do sistema, o linguista reconhece que há um elemento de imutabilidade no xadrez, a regra do jogo, que é anterior à partida e persiste após ela. Na língua, também temos esses elementos de imutabilidade: são os princípios da semiologia, regras que se verificam sempre, em toda a parte, sobrevivendo a todos os acontecimentos e se caracterizando por serem princípios gerais que, diferentemente de quaisquer entidades da língua, existem independentemente dos fatos concretos45. São, portanto, as regras mais similares às leis físicas e naturais que se aplicam à linguística (SAUSSURE, 2006).

Quando falamos da língua enquanto sistema de valores, um outro aspecto bastante relevante é apontado por Saussure (2006) através da analogia entre língua e jogo de xadrez. No capítulo intitulado Identidade, Realidades, Valores, o linguista afirma:

Por fim, todas as noções versadas neste parágrafo não diferem essencialmente daquilo que chamamos de valores. Uma nova comparação com o jogo de xadrez no-lo fará compreender (ver p. 104 s.). Tomemos um cavalo; será por si só um elemento do jogo? Certamente que não, pois, na sua materialidade pura, fora de sua casa e das outras condições do jogo, não representa nada para o jogador e não se torna elemento real e concreto senão quando revestido de seu valor e fazendo corpo com ele. Suponhamos que, no decorrer de uma partida, essa peça venha a ser destruída ou extraviada: pode-se substitui-la por outra equivalente? Decerto: não somente um cavalo, mas uma figura desprovida de qualquer parecença com ele será declarada idêntica, contanto que se lhe atribua o mesmo valor. Vê-se, pois, que, nos sistemas semiológicos como a língua, nos quais os elementos se mantêm reciprocamente em equilíbrio de acordo com regras determinadas, a noção de identidade se confunde com a de valor, e reciprocamente. (SAUSSURE, 2006, p. 128, grifo do autor)

\footnotetext{
45 Importa notarmos que os princípios da semiologia não fazem parte da língua, embora possam versar sobre ela. Para explicitarmos nosso ponto, podemos partir da afirmação de Saussure (2006) de que um critério, para reconhecermos o que é ou não é da língua, está no fato de que os fenômenos da língua nunca se efetuam em todos os tempos e em todos os lugares. Podemos partir, também, da própria definição de semiologia, visto que a mesma demonstra que ela extrapola o escopo da linguagem: "uma ciência que estuda a língua no seio da vida social" da qual a Linguística faz parte (SAUSSURE, 2006, p. 24).
} 
Em outras palavras, não interessa para a língua a materialidade dos termos; que sejam expressos por um sequência de sons x ou y não faz diferença. O que é essencial para o jogo é o valor. Percebemos, então, que o valor independe da materialidade da língua e que, além disso, a matéria não faz parte do sistema, visto que não tem efeito algum sobre ele46. Há apenas um aspecto aqui, no que tange à materialidade da língua e ao jogo, que Saussure (2002, p. 102) considera, nos Escritos de Linguística Geral, não haver base de comparação: enquanto as peças do jogo de xadrez são "indesmontáveis", as palavras (e os sintagmas de modo geral) possuem partes diversas, ou seja, são formadas a partir de unidades e subunidades, em última análise, morfemas 47.

Além de utilizar a analogia para explicar como a língua opera enquanto sistema, um dos objetivos de Saussure (2006), ao utilizar a analogia entre língua e jogo de xadrez, seria o de explicar em que medida sincronia e diacronia se distinguem. O autor afirma, no CLG, que tanto no jogo quanto na língua os estados vigentes são independentes dos estados anteriores. O ponto do linguista com tal afirmação é que, assim como um indivíduo que acompanhou toda a partida de xadrez não possui, por isso, maior vantagem para especular acerca das melhores jogadas possíveis do que aquele que chegou um minuto antes da última jogada; para entendermos como funciona um estado atual da língua, não interessa sabermos como ele se desenvolveu até chegar ao ponto presente, mas compreender como se dão suas relações atuais.

Consideramos que a observação recém feita é a que demonstra mais objetivamente a perspectiva de Saussure (2006) quando afirma que há autonomia entre sincronia e diacronia. Isso não significa, todavia, que não haja

\footnotetext{
${ }^{46}$ É por tal razão, pois, que Saussure (2006) separa língua de fala quando aborda a noção de linguagem. À língua se identifica o lado social e essencial da linguagem, enquanto a fala é individual, termo acessório e acidental. O som, Saussure (2006) deixa claro, não faz parte da língua e não passa de um instrumento do pensamento.

47 Um leitor atento poderia sugerir que esse aspecto da analogia da linguagem com o jogo de xadrez seria preservado caso pensássemos nas peças de xadrez como correlativas a unidades simples, ou seja, como morfemas. Entendemos que não haveria incongruência teórica caso Saussure (2002) fizesse tal alteração, entretanto, poderíamos objetar, com razão, que tal substituição seria prejudicial para a metáfora pelo fato de que não falamos por morfemas, de modo que os sintagmas - as palavras, nesse caso -, seriam mais representativos de como a língua opera. Ainda, a correlação entre as peças do jogo enfraqueceria o caráter solidário da língua que é verificado já nas palavras (compostas por morfemas).
} 
interdependência entre elas. O linguista reconhece que a abordagem diacrônica permite compreender melhor os estados da língua, no sentido de sabermos como determinados termos específicos tornaram-se tais nos estados atuais da língua, mas entende que a compreensão do estado da língua num todo, ou seja, enquanto sistema atual, dispensa a diacronia.

Por fim, nos ELG, Saussure (2002) explica que alguns teóricos da linguagem equipararam a língua a algum aspecto do jogo de xadrez, mas o fizeram de modo errôneo. Os que teorizaram acerca da linguística, antes da sua fundação, consideraram que a língua poderia ser comparada a uma posição do jogo de xadrez, questionando qual seria, nesse estado único do jogo, o valor das peças. Saussure (2002) observa que tal visão da língua nitidamente desconsidera os antecedentes e consequentes do estado do jogo, sendo evidentemente equivocada. Tal comparação teria, como consequência, uma estaticidade completa na língua, uma visão de língua imutável. Afirma ainda, que a gramática histórica, por sua vez, teria descoberto que há lances de xadrez na língua, mas reconheceria apenas a existência de sequência de lances, desprezando os estados de língua. A consequência evidente disso seria, por conseguinte, a impossibilidade de vislumbrar a língua enquanto sistema e de, portanto, compreender sua natureza. Nenhuma das considerações estaria correta para Saussure (2002, p. 178), pois “uma língua só é comparável à ideia completa da partida de xadrez, comportando, ao mesmo tempo, as posições e os lances, ao mesmo tempo as mudanças e os estados de sucessão”, ou seja, sincronia e diacronia.

\section{Wittgenstein e os jogos de linguagem}

Ludwig Wittgenstein foi notavelmente um dos filósofos com maior influência no século XX e um dos maiores expoentes da Virada Linguística. Em sua obra Tractatus-Logico-Philosophicus (1994), o filósofo tinha como propósito resolver todos os problemas filosóficos, problemas que ele alegava serem, na 
verdade, monstros criados pelo mau uso da linguagem. Entretanto, após a escrita do Tractatus, Wittgenstein abandona a visão de linguagem como espelho da realidade que lá defendia e, nas Investigações Filosóficas (1999), obra de 1953 publicada postumamente, inaugura o que Oliveira (2015) denomina Reviravolta Pragmática.

As principais analogias entre linguagem e jogo de xadrez se encontram nas Investigações Filosóficas (1999). Entretanto, já em 1930, o filósofo começa a realizar analogias com o jogo de xadrez, nessa época, comparando-o a sistemas axiomáticos. Mais adiante, Wittgenstein (1999) estende a analogia do jogo para toda a linguagem, vindo a fazer parte de seu aparato conceitual a expressão jogos de linguagem. A fim de que possamos compreender como a metáfora se insere dentro de seu pensamento, importa partirmos de sua definição de linguagem, que permeia toda a obra IF (1999): a linguagem é uma atividade guiada por regras.

Comecemos, então, pela noção de atividade. Após abandonar sua visão de linguagem como designação, nas IF (1999), Wittgenstein passa a vê-la como uma atividade humana dentre outras tantas, como passear, costurar, etc. Ela é uma atividade por haver identidade entre ação e linguagem e porque, como bem sublinha Oliveira (2015), a linguagem se realiza em contextos de ação diversos e, portanto, só pode ser compreendida dentro do contexto de ação em que se insere. Assim, a linguagem está ligada às práticas gerais de uma comunidade linguística, ou seja, de uma forma de vida. Sendo a noção de forma de vida definida como junção de cultura, visão de mundo e linguagem (GLOCK, 1998), é uma prática humana que se interliga às nossas práticas não linguísticas, influenciando e sendo influenciada por elas. Wittgenstein (1999, p. 35, §23), ao afirmar que "a expressão ‘jogo de linguagem' deve enfatizar aqui que o falar de uma língua é parte de uma atividade ou de uma forma de vida”, quer dizer que os jogos de linguagem estão imersos em nossa forma de vida, de modo que o significado das palavras só pode ser compreendido levando-se em consideração os contextos proporcionados por ela.

Mas, afinal, o que são jogos de linguagem? Wittgenstein (1999) não considera possível dar uma definição dessa expressão, visto que, para o filósofo, 
os jogos se aproximam por semelhança de família 48 . No entanto, trata desse termo em quatro acepções diferentes, sendo que a que mais nos interessa é a dos jogos de linguagem como as atividades linguísticas, que contrapõem-se a atividades não linguísticas (GLOCK, 1998). Exemplos de jogos como atividades linguísticas são os atos de fala enumerados em IF (WITTGENSTEIN, 1999): comandar, descrever um objeto conforme as aparências, relatar um acontecimento, conjecturar, mentir, relatar sonhos, formular hipóteses, etc. Notemos, pois, que, se a forma de vida é uma prática que engloba tanto atividades linguísticas como não linguísticas, e, se os jogos de linguagem são parte da forma de vida, sendo entendidos como atividades linguísticas; logo, os jogos de linguagem dizem respeito à toda a parte da forma de vida que concerne à linguagem.

Agora que se compreende o porquê da linguagem ser uma atividade, cumpre passar à afirmação de que essa atividade é guiada por regras. Considerese, primeiramente, a seguinte passagem:

\footnotetext{
Quando se mostra para alguém o rei no jogo de xadrez e se diz "Este é o rei”, não se explica para essa pessoa, com isso, o uso desta peça - a não ser que ele já conheça as regras do jogo salvo esta última definição: a forma da peça do rei. [...] A forma da peça do jogo corresponderia aqui ao som ou à forma de uma palavra. (WITTGENSTEIN, 1999, p. 38, §31)
}

Com tal analogia, o filósofo pretende mostrar que, assim como apontar para o elemento material do xadrez e mostrá-lo a alguém não explica como ele funciona no jogo, do mesmo modo apontar para um elemento material da língua - o som ou a forma de uma palavra - não explica como ela é utilizada nos contextos de linguagem; não explica seu significado. O filósofo, nessa passagem,

\footnotetext{
48 Wittgenstein (1999) ia na contramão das teorias essencialistas do significado e afirmava haver uma multiplicidade irredutível de jogos de linguagem, de modo que só poderiam ser determinados por semelhanças de família (GLOCK, 1998). Se pensarmos na expressão semelhanças de família em seu uso ordinário, concordaremos que um filho pode ter herdado maiores características do seu pai, assim como um outro filho pode se assemelhar mais com sua tia e com seu avô, todos eles sendo reconhecidos como membros da mesma família, mesmo que não haja um traço comum a todos eles. Da mesma forma, não podemos definir a expressão jogos de linguagem a partir de um traço comum a todos os jogos, porque eles possuem apenas semelhanças de família; o jogo de damas se aproxima mais do jogo de xadrez e se distancia do jogo de sinuca, mas, de qualquer modo, todos são jogos.
} 
já indica que aquilo que importa para a compreensão do uso da peça é o conhecimento das regras do jogo. Todavia, o objetivo aqui não é dar ênfase à noção de regra, mas descartar a materialidade dos elementos da língua como importantes para compreender-se o uso das palavras.

Em IF (WITTGENSTEIN, 1999, p. 65, §108), por sua vez, tem-se não só o ponto anterior reiterado como também um avanço explicativo do filósofo no que tange à noção de regra: “[...] falamos deles [dos fenômenos espaciais e temporais da linguagem] tal como falamos de figuras do jogo de xadrez, indicando suas regras, e não descrevendo suas propriedades físicas". Vemos aqui que compreenderemos o modo como uma palavra será utilizada explicando suas regras de uso. Se há regras de uso, então há possibilidade de transgressão. Isso significa, por conseguinte, que serão as regras que determinarão se o jogador está jogando de modo correto ou incorreto, se o locutor está utilizando as palavras da língua de modo adequado ou inadequado.

Quando fazemos tais afirmações, imediatamente surge a questão: o que é uma jogada correta e uma jogada incorreta? O que as diferencia? Wittgenstein (1999, p. 48, §54) responde essa questão após indagar qual seria o critério de correção para sabermos se uma pessoa está utilizando as regras adequadamente:

"[...] dizemos que se joga segundo esta ou aquela regra, porque um observador pode ler essas regras na práxis do jogo [...]. Mas como o observador distingue, nesse caso, entre um erro de quem joga e uma jogada certa?" e responde: "Há para isso indícios no comportamento dos jogadores".

É importante notar que, para Wittgenstein (1999), as regras constitutivas da linguagem são as regras da gramática. Gramática, na concepção desse autor, deve ser compreendida como "o sistema global de regras gramaticais, das regras constitutivas que as definem, pela determinação daquilo que faz sentido dizer ao usá-las" (GLOCK 1998, p. 193, grifo nosso). Em outras palavras, regras são tomadas como padrões de correção, não no sentido de descreverem como as pessoas falam, mas de delimitar o que é falar com sentido49. Assim, quando o

${ }^{49}$ Assim como os jogos de linguagem, as regras também não possuem uma definição precisa, 
filósofo afirma que perceberemos se a jogada é correta ou incorreta através do comportamento dos jogadores, ele quer dizer que devemos analisar se o uso que o locutor faz de uma palavra é correto ou incorreto no que tange ao aspecto pragmático das palavras. Em outros termos, quando utilizamos as palavras, nós agimos e, desse modo, nos comportamos de uma determinada maneira; nosso comportamento será avaliado através da análise pragmática do que dizemos, o que, por sua vez, permitirá estabelecer se utilizamos a linguagem correta ou incorretamente.

Glock (1998) explica que, para Wittgenstein (1999), assim como o movimento de uma peça corresponde a um lance no jogo de xadrez, uma proposição corresponde a um lance no jogo da linguagem; dessa forma, certas jogadas serão aceitas, enquanto outras serão rejeitadas. Assim, se um indivíduo utilizasse determinado termo que não faz sentido em um determinado contexto, um sujeito wittgensteiniano poderia muito bem dizer: "Você não está utilizando a regra corretamente”. Logo, fazendo uma analogia com o jogo de xadrez, podemos dizer que seria como se o sujeito estivesse jogando xadrez com as regras do jogo de damas.

Percebemos, então, que a noção de regra possui forte conexão com a noção de significado. O filósofo deixa claro em IF (WITTGENSTEIN, 1999) que o significado de um termo é o seu uso na linguagem, ou seja, que o uso que fazemos de um signo determina seu sentido. Assim, esse uso que fazemos não pode ser desordenado; há regras para tal, e tais regras delimitam os sentidos possíveis de um signo, considerando-se sempre os contextos de comunicação em que os empregamos.

Tendo isso em mente, Wittgenstein (2001, p. 3) aproxima as peças de xadrez às palavras da língua, afirmando que "palavras e peças de xadrez são análogas: saber como usar uma palavra é como saber como mover uma peça de xadrez" ${ }^{\circ}$. Com isso, o autor busca salientar que, assim como aprendemos o

podendo ser explicadas apenas por semelhanças de família.

50 Apesar de o objeto de nosso estudo em Wittgenstein (1999) ser, neste artigo, a obra Investigações Filosóficas (1999), optamos por incluir essa citação da obra Wittgenstein's Lectures (2001), visto que ela complementa o que o filósofo afirma nas IF acerca da analogia entre linguagem e jogo de xadrez. 
xadrez através da aprendizagem do movimento das peças, aprendemos o significado das palavras aprendendo a utilizá-las (GLOCK, 1998), ou seja, aprendemos ao nos engajarmos em atividades linguísticas, em jogos de linguagem. Logo, será no uso que o significado das palavras será determinado e será através do uso que aprenderemos as regras de utilização, podendo, assim, distinguir a utilização correta da incorreta.

Importa sabermos ainda que Wittgenstein (1999, p. 92, §199, grifo do autor) relaciona o seguimento de regras da linguagem a um hábito, e menciona aqui o jogo de xadrez:

Seguir uma regra, fazer uma comunicação, dar uma ordem, jogar uma partida de xadrez são hábitos (costumes, instituições). Compreender uma frase significa compreender uma linguagem. Compreender uma linguagem significa dominar uma técnica.

Podemos afirmar que, no jogo de xadrez, a partir do momento em que dominamos bem as regras do jogo, aplicamos as mesmas a cada partida sem necessitarmos refletir sobre o motivo de estarmos realizando o movimento que é característico de cada peça. Entretanto, no momento em que nos questionassem: "Por que no início da partida você moveu duas casas com o peão, mas o outro jogador moveu apenas uma?”, saberíamos responder que é facultativo ao jogador mover uma ou duas casas com o peão no primeiro lance do jogo. Isso, para Wittgenstein (1999), significa seguir uma regra e se qualifica como um hábito, costume, que se justifica justamente por dominarmos a técnica do jogo. Da mesma forma, quando dominamos nossa língua materna, passamos a utilizá-la no momento da fala sem pensarmos exatamente no porquê de estarmos empregando esta ou aquela palavra. Nós dominamos essa técnica, mas, caso nos perguntem o motivo de utilizarmos uma palavra ao invés de outra, saberemos explicar nossa escolha. Assim, seguimos as regras da língua e estamos habituados a elas, o que só é possível porque durante o aprendizado da língua aprendemos suas normas de aplicação, de modo a sabermos utilizar os diversos jogos de linguagem que estão imersos em nossa forma de vida. 
Por fim, notemos que, apesar de considerar a capacidade de utilizar a língua fruto do hábito, o filósofo não vê o uso da linguagem de modo mecânico, mas considera que as regras operam como um padrão referencial intersubjetivo, que determina os limites de ação linguística dos indivíduos e, ao mesmo tempo, permite um espaço de liberdade ao falante (OLIVEIRA, 2015). Do mesmo modo, no jogo de xadrez, o indivíduo possui plena liberdade para escolher qual peça mover em cada jogada, desde que as mova segundo as regras estabelecidas pelo jogo, na língua os falantes possuem liberdade para se expressarem e se engajarem em inúmeros jogos de linguagem, desde que o façam de acordo com as regras estabelecidas por cada um desses jogos que, por sua vez, estarão submetidos à forma de vida em que se está engajado. Para Wittgenstein (1999), então, linguagem é praxis social (OLIVEIRA, 2015).

\section{Análise comparativa das analogias}

Tendo em vista o que foi explanado acerca da metáfora do jogo de xadrez no pensamento dos autores, consideremos, agora, as analogias que se apresentaram como mais significativas em ambas teorias, investigando em que medida podemos aproximá-las, quando as comparamos entre si, e analisar sua coerência no que tange à relação entre língua/linguagem e jogo de xadrez.

Materialidade das peças: primeiramente, o ponto de maior convergência entre ambos pensadores está no fato de os dois identificarem, nas analogias, as peças de xadrez às palavras da língua. As palavras são, pois, abordadas em seus aspectos materiais. No caso de Wittgenstein (1999), fica claro que o correlato material da peça de xadrez seria o som e a representação escrita da palavra, enquanto que, para Saussure (2002; 2006), seria apenas o som, visto que, continuamente no Curso de Linguística Geral, o autor afirma ser essa a parte material da língua. Notemos, ainda, que, nos dois casos, as analogias visam mostrar que o aspecto material da língua não importa, seja para defini-la enquanto sistema, seja para explicar seu uso: para Wittgenstein (1999), a 
materialidade da palavra não explica como ela pode ser usada; enquanto para Saussure (2002; 2006), a materialidade não afeta o sistema, ou seja, não faz parte dele. Consideramos, pois, que, para os dois autores, há coerência quando avaliamos a importância do elemento material tanto no xadrez quanto na língua, visto que em ambos os casos a materialidade das peças é acessória.

Regras do jogo: percebemos que tanto Saussure (2006) ${ }^{11}$ quanto Wittgenstein (1999) dão importância à noção de regra, mas a tratam de modo diferente, tendo objetivos distintos: o objetivo de Saussure com a analogia é apontar a imutabilidade das regras - os Princípios da Semiologia - e sua persistência na passagem de uma sincronia a outra; Wittgenstein (1999), por sua vez, salienta o aspecto regulativo das regras da língua, mostrando que elas limitam as jogadas e, ao mesmo tempo, permitem liberdade dentro de seus limites. Notemos que, na teoria wittgensteiniana, as regras possuem maior flexibilidade, visto serem suscetíveis a mudanças ao longo do tempo, já que fazem parte de uma forma de vida. Isso não significa, entretanto, que não haja flexibilidade no sistema de Saussure (2006): o que ocorre é que a flexibilidade não está nas regras enquanto princípios semiológicos, mas nos valores, que mudam a cada lance do jogo52.

Ainda no que tange ao mesmo tema, importa reiterarmos, também, que Wittgenstein (1999) considera não ser possível dar uma definição de regra, visto que elas são definidas não a partir de uma concepção essencialista, mas por semelhanças de família. Tendo isso em mente, podemos dizer que, enquanto para Saussure (2006) as regras do jogo de xadrez seriam princípios imutáveis e aparentemente definidos, mas que não estão imediatamente claros quais sejam;

\footnotetext{
${ }^{51}$ Visto que há a possibilidade de interpretar o funcionamento das regras de modo diferente nos ELG (2002) (vide nota 12), saliento que as observaçoes feitas sobre as regras do jogo se baseiam especificamente no CLG (2006).

$5^{2}$ Loïc Depecker (2012), na obra Compreender Saussure a partir dos manuscritos, faz uma afirmação que diverge do que observamos no CLG quanto ao distanciamento entre as regras do xadrez e as regras da língua. O autor interpreta que, para Saussure (2002), enquanto no jogo de xadrez as regras se mantêm inalteradas; na língua, estão submetidas às mudanças de valor, sendo, portanto, mutáveis. Tal afirmação tem como base principal as Notas de Émile Constantin, aluno de Saussure cujos cadernos não foram incluídos no CLG e que, naturalmente, não fazem parte dos ELG. Consideramos relevante apontar a possibilidade interpretativa, todavia, visto que a obra mencionada não é nosso objeto de estudo nesse momento, nos limitamos a mencionar a existência dessa interpretação.
} 
para Wittgenstein (1999), seriam uma infinidade de regras que não poderiam ser definidas antes do próprio jogo. Os jogadores aprenderiam por costume, hábito, a jogar com os demais, sem ter essas regras definidas numa lista fixa e acabada, mas saberiam utilizá-las e exemplificar aos demais, ao longo da partida, como se joga, além de poderem mostrar ao outro jogador quando este não estivesse seguindo a regra.

Por fim, podemos dizer que, em Saussure (2006), as regras da língua se assemelham às regras do jogo de xadrez num sentido identitário, uma vez que, além de as regras nos dois casos serem imutáveis, elas se assemelham em sua estrutura de funcionamento, operando de modo similar tanto no jogo de xadrez quanto na língua. Para Wittgenstein (1999), acreditamos haver uma correspondência estrutural - dado que as regras operam com função similar nos dois casos -, mas falta identificação completa, já que, na língua, as regras são frequentemente mutáveis, ao passo que no xadrez são fixas.

Lances do jogo: notemos, ainda, que a movimentação das peças possui função diferente em ambas as metáforas. O objetivo de Saussure (2002; 2006) é mostrar que uma alteração em um signo repercute sobre todo o sistema. Utiliza o movimento de uma peça como correspondente a uma mudança no sistema da língua, e, por conseguinte, à passagem de uma sincronia a outra. Em Wittgenstein (1999), o objetivo da analogia é mostrar que o significado das palavras é regulado pelo seu uso regrado. Assim, o filósofo utiliza os lances do jogo para representar nossas atividades linguísticas portadoras de significado e se importa em identificar um lance incorreto com a aplicação inadequada de uma regra num jogo de linguagem. Acrescentemos que Saussure (2002; 2006) não só aborda a analogia do xadrez e linguagem no aspecto dos lances, mas também como uma posição de jogo, equiparando-a a um estado de língua. Wittgenstein (1999) não utiliza a analogia sob esse aspecto.

Consideramos, pois, no que tange aos lances do jogo, que, em ambos os casos, há correspondência no modo de operação do xadrez e da língua: para Saussure $(2002 ; 2006)$, tanto no caso do jogo quanto da língua, os lances modificam o sistema no qual estão inseridos; para Wittgenstein (1999), um lance 
incorreto, seja no jogo, seja na língua, corresponde a uma aplicação inadequada de alguma regra.

Valor x Significado: por fim, importa notarmos ainda que, enquanto a metáfora do jogo de xadrez em Wittgenstein (1999) dá destaque à noção de significado, em Saussure $(2002 ; 2006)$ o enfoque se direciona à noção de valor53. No caso de Wittgenstein (1999), vimos que o filósofo objetiva defender que o significado adequado de uma palavra (que equivale a uma peça) advém da aplicação correta em um contexto de uso, utilizando a analogia dos lances do jogo para mostrar seu ponto. Visto que o filósofo não se preocupa em analisar a língua enquanto sistema, a noção de valor é inexistente em seu pensamento. Saussure (2002; 2006), por sua vez, como objetiva explicar justamente o funcionamento da língua enquanto sistema, utiliza o jogo de xadrez para explicar que, em ambos os casos, temos um sistema cujas relações entre termos se dá por oposição, trazendo à tona a noção de valor.

Quanto à coerência das analogias, importa atentar que, para Saussure (2002; 2006), enquanto o valor na língua diz respeito especificamente às relações gerais dos termos uns com os outros, sendo impossível afirmarmos que uma mudança na língua seja melhor que outra; no jogo de xadrez, o valor possui caráter qualitativo, visto que ele aumenta ou diminui conforme uma peça passa a ser mais ou menos benéfica para eliminar uma peça adversária. Ou seja, apesar de haver coerência na visão de jogo e língua como sistemas de valores, sob o aspecto recém descrito, não há identidade. Para Wittgenstein (1999), por fim, compreendemos haver coerência analógica na medida em que podemos inferir do pensamento do filósofo que, assim como um lance incorreto implica um jogo inadequado às regras, do mesmo modo, um uso de palavra inadequado gera um significado inadequado ao contexto.

\footnotetext{
53 Embora o enfoque seja dado ao valor, isso não significa que Saussure (2006) não se importe com a noção de significação. De fato, a noção de significação/sentido se apresenta como fundamental por ela ser um dos componentes do signo linguístico, sendo, portanto, distinta do termo valor. Os dois termos, pois, evocam relações diferentes. Como Normand (2009) sublinha, a significação envolve a relação interior do signo linguístico, ao passo que o valor diz respeito às relações de um signo com os demais signos que os rodeiam. Ainda assim, significação e valor são íntimos, visto que o significado só pode existir a partir das relações de oposição entre os signos e que um signo, fora desse sistema de oposições, nada significa.
} 


\section{Considerações Finais}

A partir de nossa exposição, acreditamos ser possível perceber que Saussure $(2002$; 2006) apresenta a metáfora do jogo de xadrez de modo bastante sistemático e direto, utilizando-a a fim de clarificar como a língua funciona enquanto sistema e como a complexa noção de valor ali dentro opera. Wittgenstein (1999), por sua vez, não é tão detalhista em sua exposição sobre a metáfora, não explora tanto os diferentes aspectos do jogo de xadrez quanto Saussure $(2002 ; 2006)$ e realiza as analogias de modo disperso ao longo da obra, o que é característico da escrita não técnica e aforística das Investigações Filosóficas (WITTGENSTEIN, 1999). Além disso, para compreendermos a metáfora de modo mais aprofundado em Wittgenstein (1999), é necessário recorrer a várias outras passagens que elucidam outros aspectos de sua visão de linguagem e que só indiretamente se relacionam a ela. De qualquer modo, a metáfora se apresenta e mostra sua importância a partir do momento em que o filósofo busca explicar sua definição de linguagem como atividade regrada e evidencia como ocorre a relação de tal noção com a ideia de que significado é uso.

Importa notar, ainda, que a escolha dos termos língua/linguagem, respectivos a Saussure (2002; 2006) e Wittgenstein (1999), diz respeito aos fenômenos linguísticos investigados por cada pensador: Saussure (2002; 2006), como já mencionamos, pensa a linguagem como constitutiva de dois lados, um social e um individual, mas se interessa sobretudo pelo aspecto social da linguagem, que define como língua. Wittgenstein (1999), a seu turno, utiliza o termo língua em diversos momentos das IF, entretanto, de modo geral, o faz quando se refere a línguas particulares; seu interesse pelo fenômeno de como as palavras significam advém da ideia de linguagem, pois dá especificamente a ela o caráter de atividade.

Apesar da diferença terminológica mencionada, comprendemos que, em ambos os autores, os termos escolhidos expressam fenômenos linguísticos globais: Saussure (2002; 2006) pensa a língua em seu funcionamento sistemático, enquanto Wittgenstein (1999) reflete sobre o aspecto pragmático da 
linguagem. Em outros termos, da mesma forma que, para Saussure (2002; 2006), todas as línguas existentes operam enquanto sistemas cujas relações entre signos ocorrem por oposição - o que justamente nos permite afirmar que a língua é um sistema de signos -; para Wittgenstein (1999), a linguagem é uma atividade guiada por regras em qualquer língua que se possa pensar, assim como o significado das expressões existentes em cada língua são dependentes de seus contextos de enunciação.

Ademais, assim como é relevante notar a terminologia distinta dos dois pensadores, consideramos haver uma distinção metodológica interessante em seu pensamento: enquanto Saussure $(2002$; 2006) dá importância secundária à fala, por esta ser o aspecto individual da linguagem54, Wittgenstein (1999) pensa a linguagem a partir de um ponto de vista pragmático, do uso contextual da língua, o que o aproxima mais de uma reflexão sobre o que seria, em termos saussurianos, a fala.

Por fim, com base em nossa investigação, acreditamos não ser possível afirmar que exista uma vasta identificação entre as analogias de ambos; entretanto, podemos dizer que há uma série de elementos no pensamento dos dois intelectuais que, se não se identificam, tratam a língua a partir de aspectos similares do xadrez. Tais similaridades nos permitem compreender, por diferentes lentes, como língua/linguagem podem se aproximar do jogo de xadrez e o porquê de tantos pensadores terem feito uso dessa metáfora.

\footnotetext{
54 Ressaltamos que essa importância secundária é estritamente metodológica e que não significa exclusão da fala. É importante frisar, aqui, que Saussure (2002; 2006) não exclui a fala de suas teorizações, pois, tanto no CLG quanto nos ELG, encontramos a preocupação com a implicação mútua de língua e fala, o que se comprova na afirmação do linguista de que "nada entra na língua sem ter sido antes experimentado na fala, e todos os fenômenos evolutivos têm sua raiz na esfera do indivíduo" (SAUSSURE, 2006, p. 196). Metodologicamente, no entanto, a linguística da fala derivaria da linguística da língua.
} 


\section{Referências}

DEPECKER, Loïc. Compreender Saussure a partir dos manuscritos.

Petrópolis: Vozes, 2012.

DUCARD, Dominique. Language and the game of chess: Saussure, Hjelmslev, Wittgenstein and Greimas. Semiotica, v. 214, p. 199-217, jan. 2017.

DUIT, Reinders. The role of analogies and metaphors in learning science.

Science Education, v. 75, n. 6, p. 649-672, 1991.

GLOCK, Hans-Johann. Dicionário Wittgenstein. Rio de Janeiro: Jorge Zahar, 1998.

GUSTAFSSON, Martin. Wittgenstein on using language and playing chess: the breakdown of an analogy, and its consequences. In: BERMON, Emmanuel; NABOUX, Jean Philippe. Finding One's Way Through Wittgenstein's Philosophical Investigations - New Essays on §§1-88. Dordrecht: Springer, 2017. p.79-93.

NORMAND, Claudine. Saussure. São Paulo: Estação Liberdade, 2009.

OLIVEIRA, Manfredo de. Reviravolta linguístico-pragmática na filosofia contemporânea. São Paulo: Edições Loyola, 2015.

SAUSSURE, Ferdinand de. Escritos de Linguística Geral. São Paulo:Editora Cultrix, 2002.

SAUSSURE, Ferdinand de. Curso de linguística geral. São Paulo: Cultrix, 2006.

WITTGENSTEIN, Ludwig. Tractatus logico-philosophicus. São Paulo: Edusp, 1994.

WITTGENSTEIN, Ludwig. Investigações filosóficas. São Paulo: Nova Cultural, 1999.

WITTGENSTEIN, Ludwig. Wittgenstein's lectures: Cambridge, 1932-1935.

New York: Prometheus Books, 2001.

Artigo recebido em 16 de maio de 2020 e aceito em 6 de julho de 2020. 